\title{
Direct Diels-Alder reaction of chitin derived 3-acetamido-5-acetylfu-
}

\section{ran}

Juliana G. Pereira,[a] João M. J. M. Ravasco,[a] João R. Vale,[a] Fausto Queda,[b] Rafael F. A. Gomes*[a]

[a] Research Institute for Medicines (iMed.ULisboa), Faculty of Pharmacy, University of Lisbon; Avenida Professor Gama Pinto, 1649-003, Lisbon (Portugal).

[b] AlmaScience Colab, Madan Parque, 2829-516 Caparica (Portugal)

Diels-Alder $\bullet$ biomass $\bullet$ chitin $\bullet$-acetamido-5-acetylfuran $\bullet$ renewables

\begin{abstract}
The Diels-Alder (DA) reaction of biomass derived furans is an emerging technology for the preparation of new molecular entities and "drop-in" commodity chemicals. In this work we address the challenge of the direct use of electronpoor furanic platforms as dienes through the use of an unexplored chitin derived furan, 3-acetamido-5-acetylfuran ( $3 \mathrm{~A} 5 \mathrm{AF}$ ). The 3-acetamido group promoted a remarkable increase in the kinetics of the DA allowing for the preparation of 7oxanorbornenes (7-ONB) at $50^{\circ} \mathrm{C}$. Partial hydrolysis of the enamide to hemi-acylaminals was possible upon fine tuning of the reaction conditions, disabling retro-DA processes. Finally, DA reaction of the reduced form of $3 \mathrm{~A}_{5} \mathrm{AF}$ allowed quantitative formation of 7 -ONB in aqueous condition after 10 minutes. Certanly these are the first steps for expanding the toolbox of chitin derived $3 \mathrm{~A}_{5} \mathrm{AF}$ as diene.
\end{abstract}

The Diels-Alder (DA) cycloaddition of furans have been subject of extensive research as of late, in particular, employing biomass derived furans such as furfural and 5-hydroxymethylfurfural (HMF)..$^{1-3}$ Both these furans have been depicted as part of Bozel's list of top $10+4$ biobased products from carbohydrates 4 and they have been reported in several seminal applications in a variety of areas (e.g. materials, energy, drug discovery).3, 5-17 Importantly, furfural/HMF derivatives undergo reversible DA with dienophiles to yield 7oxanorbornenes (7-ONB). This dynamic character has solely led to extensive research on understanding interactions and mechanistic nuances governing furan diene/dienophile DA and fine tuning reactants to bypass reactivity stability of the 7 -ONB products issues (Scheme $1 \mathrm{~A}$ ). ${ }^{18-23}$ In this sense, the furan DA technology has expanded to create stimuli responsive frameworks of the utmost importance in material chemistry ${ }^{24}$, stable adducts usefull for drug discovery, ${ }^{25}$ amongst others. ${ }^{26}$ However, mostly electron rich furans are paired with electron poor dienophiles, meeting the conditions imposed by the Frontier Molecular Orbital (FMO) theory. This particularity renders the use of electron withdrawing biomass derived furfural and HMF "as is" a challenging task, as the electronic mismatch does not permit the reaction. Efforts to overcome this problem led to Brandvold in 2010 patenting the transformation of HMF to dimethylfuran (DiMF), towards the formation of biobased $p$-xylene ${ }^{27}$ via DA in an elegant sequential strategy to prepare "drop-in" chemicals from bio-refinery derivatives. Further optimization ${ }^{28-30}$ led to a one pot procedure from HMF to $p$-xylene. ${ }^{31}$ A different approach designed by Ananikov and co-workers relied on the simple reduction of HMF to the corresponding 2,5-bis(hydroxymethyl)furan (BHMF), thus allowing the $[4 \pi+2 \pi]$ cycloaddition with maleimide. However, retro-DA of the $7-\mathrm{ONB}$ hindered the isolation of the adduct, mandating for a tandem hydrogenation to bypass this issue. ${ }^{18}$ Bruijnincx and coworkers recently reported a similar strategy, by trapping the DA adduct of furfuryl alcohol and activated acrylates yielding stable lactones. ${ }^{19}$

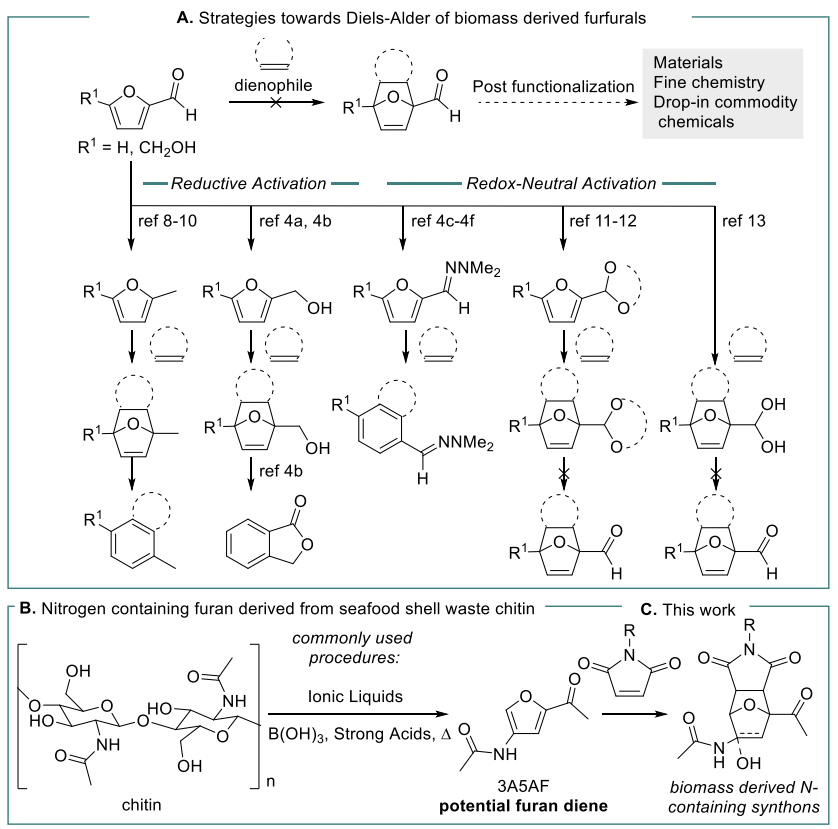

Scheme 1. A. Employed strategies towards Diels-Alder cycloadditions of biomass derived furfurals; B. Nitrogen containing furan $3 \mathrm{~A}_{5} \mathrm{AF}$ derived from seafood shell waste chitin C. Direct Diels-Alder cycloadditions on $3 \mathrm{~A}_{5} \mathrm{AF}$ (this work). 
Unfortunately, these approaches require reduction of the biomass derived furfurals, which is not ideal when aiming at producing functionalizable derivatives. "Redoxneutral" strategies rely on masking the aldehydes either by hydrazone condensation ${ }^{20-23}, 3^{2}$ (which often undergoes spontaneous post-DA aromatization) or the temporary installment of acetals, as reported by the groups of Jérôme and Dumesic. ${ }^{2-36}$

However, this latter example was shown that upon deprotection of the acetal, molecular orbital mismatch promotes complete retro-DA, affording HMF and maleimide. Noteworthy, Bruijnincx and coworkers observed that under concentrated aqueous solution, biomass derived furfurals underwent tandem DA reaction/aldehyde hydration in the presence of maleimides. 37 The same authors also observed a counterintuitive DA of carboxylic acids derived from furfural and HMF under basic conditions. ${ }^{8}$

All the advances on biomass furan DA chemistry have relied on lignocellulosic derived furans, leading to products that are themselves rich in carbon and oxygen.

However, an overlooked largely available waste byproduct, chitin, can be readily transformed into $\mathrm{N}$-containing furan 3acetamido-5-acetyl-furan (3A5AF).39 Since over 5 million tons of seafood shells are produced, which contains $15-40 \%$ chitin by weight, $4^{\circ}$ it can be envisioned that $3 \mathrm{~A}_{5} \mathrm{AF}$ will play an important role as a key biomass derived $\mathrm{N}$-containing synthon (Schem 1 B).

Based on previous examples of furan DA reactions of substrates bearing 2 -amino ${ }^{41}$ and 3 -amino substituents, ${ }^{42}$ we enquired whether the amido group of ${ }_{3} \mathrm{~A}_{5} \mathrm{AF}$ allowed the direct DA reaction of this carbonyl-containing furan derivate with a model dienophile, thus bypassing orbital restriction of furfural, 2-acetyl furan (AF) or even HMF (Scheme $1 C$ ). The selected model was maleimide, being a bis-activated dienophile shown to undergo DA with a variety of furanic scaffolds. To strengthen the hypothesis, density functional theory (DFT) studies revealed a HOMO-LUMO gap for the $3 \mathrm{~A}_{5} \mathrm{AF} /$ maleimide pair of $5.86 \mathrm{eV}$, in comparison with $6.35 \mathrm{eV}$ for acetylfuran(AF)/maleimide and $6.32 \mathrm{eV}$ for $\mathrm{HMF} /$ maleimide (Scheme $2 \mathrm{~A}$ ). The significant decrease of the $\mathrm{HOMO}$ by $0.5 \mathrm{eV}$ of $3 \mathrm{~A}_{5} \mathrm{AF}$ in comparison with $\mathrm{AF}$ was previously observed in indirect activation strategies of furfu$\mathrm{ral} / \mathrm{HMF}$ to furfuryl alcohol/BHMF. ${ }^{18,35}$ Ananikov and coworkers recently observed a strong correlation between the HOMO of furan dienes and the free activation energy for the reaction. ${ }^{43}$ Accordingly the mechanism of the reaction was evaluated by DFT performed at the Mo6L/6$311+\mathrm{G}(\mathrm{d}, \mathrm{p}) / \mathrm{SMD}$ (water)// Mo6L/6-31G(d) level of theory. Indeed a $\Delta \mathrm{G}^{\ddagger}$ difference $>3 \mathrm{kcal} . \mathrm{mol}^{-1}$ was observed when comparing $3 \mathrm{~A}_{5} \mathrm{AF}$ with $\mathrm{AF}$ and $\mathrm{HMF}$. Moreover, a $\Delta \mathrm{G}$ of -6.3 kcal.mol-1 and -8 kcal.mol-1 for endo-ra and exo-1a correspondingly (Scheme $2 \mathrm{~B}$ ) indicates the reaction is exergonic in nature, which should hinder retro cyclization processes.

Herein we explored the first direct DA reaction of biomass derived furans towards the preparation of novel $\mathrm{N}$-containing synthons.
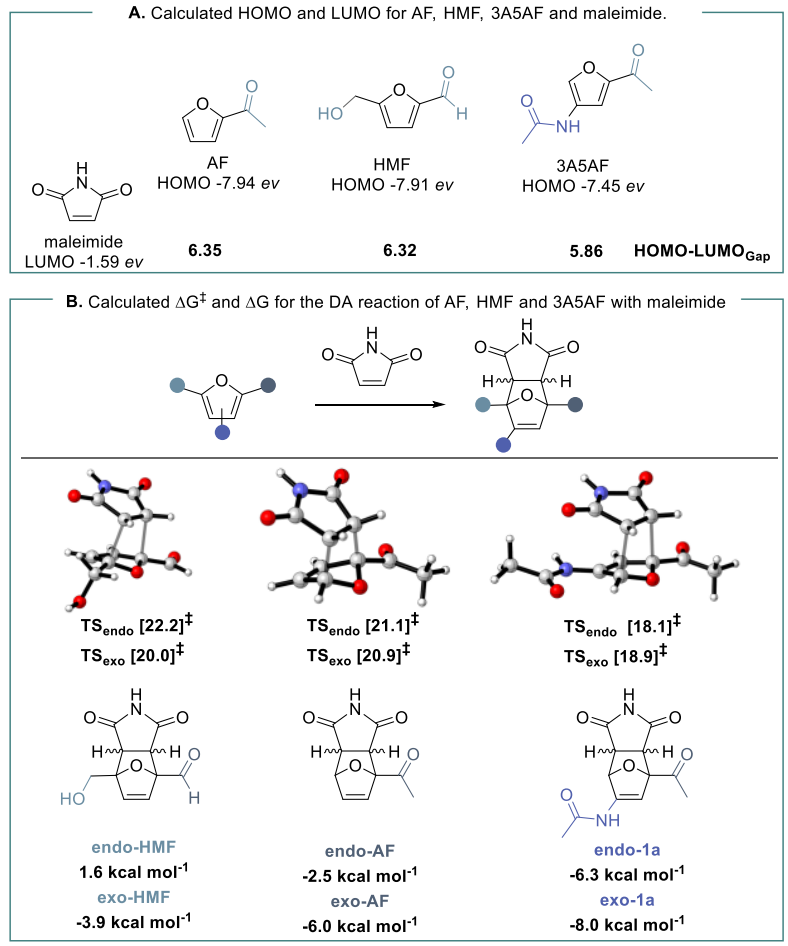

Scheme 2. A. Calculated HOMO and LUMO for AF, HMF, $3 \mathrm{~A}_{5} \mathrm{AF}$ and maleimide. B. Calculated $\Delta \mathrm{G}^{\ddagger}$ and $\Delta \mathrm{G}$ for the $\mathrm{DA}$ reaction of $\mathrm{AF}, \mathrm{HMF}$ and $3 \mathrm{~A}_{5} \mathrm{AF}$ with maleimide. DFT studies were performed at the Mo6L/6-311+G(d,p)/SMD(water)// Mo6L/6-31G(d) level of theory.

We initiated our endeavors by reacting $3 \mathrm{~A}_{5} \mathrm{AF}$ with model unsubstituted maleimide in DMSO- $\mathrm{d}_{6}$ under different temperatures (Table 1, Entries 1 - 5). We observed that the reaction afforded a single product in $80 \%$ yield under $50^{\circ} \mathrm{C}$ after 24 hours (Table 1, Entry 4), with no improvement of yield after $48 \mathrm{~h}$. This product was identified as the exo isomer of 7 -ONB 1 a (for more information see SI).

Surprisingly, no endo product was detected by ${ }^{1} \mathrm{H}-\mathrm{NMR}$ under the aforementioned reaction conditions. Limitations of the starting material solubility led to no conversion in most commonly used solvents for furan DA such as THF, dioxane, dichloromethane and chloroform (Table 1, Entries 6 - 9). Despite being soluble in acetonitrile and methanol, both led to poor yields of $1 \mathbf{a}$ (Table 1, Entries 10 and 11 ).

The acceleration of DA reaction in water via hydrophobic effect has been thoroughly studied, 44 and has found its use on biomass furan DA chemistry. ${ }^{37}$ In fact, one of the earliest reports on faster kinetics of DA reactions in water concerned furan and maleic anhydride. 45

Aiming at improving the yields of DA adduct 1a, the on water effect was studied by performing the reaction in DMSO$\mathrm{d}_{6}: \mathrm{D}_{2} \mathrm{O}$. Under these conditions, a new product $2 \mathrm{a}$ was formed, corresponding to the partial hydrolysis of the enamide into a hemi-acylaminal (Scheme 3). 
Table 1. Reaction optimization. ${ }^{[a]}$

\begin{tabular}{|c|c|c|c|c|}
\hline & $3 A 5 A$ & & exo-1a & \\
\hline Entry & Solvent & Temp. $\left({ }^{\circ} \mathrm{C}\right)$ & Time (h) & $\begin{array}{c}\text { exo-1a } \\
(\%)^{[b]}\end{array}$ \\
\hline 1 & DMSO & $\mathrm{rt}$ & $48 \mathrm{~h}$ & o \\
\hline 2 & DMSO & 40 & 12 & 25 \\
\hline 3 & DMSO & 50 & 12 & 43 \\
\hline 4 & DMSO & 50 & 24 & 80 \\
\hline 5 & DMSO & 50 & 24 & 80 \\
\hline 6 & THF & 50 & 24 & o \\
\hline 7 & Dioxane & 50 & 24 & o \\
\hline 8 & DCM & 50 & 24 & o \\
\hline 9 & $\mathrm{CHCl}_{3}$ & 50 & 24 & o \\
\hline 10 & $\mathrm{MeCN}$ & 50 & 24 & 21 \\
\hline 11 & $\mathrm{MeOH}$ & 50 & 24 & 35 \\
\hline
\end{tabular}

[a] Reaction conditions: 3A5AF (6 mg, o.035 mmol), maleimide (3.8 mg, 1.1 equiv), solvent (o.4 mL, o.09M). [b] Yield determined by ${ }^{1} \mathrm{H}-\mathrm{NMR}$.

$\mathrm{X}$-ray crystallography of a crystalline derivative from $\mathbf{2 a}$ obtained from the reaction of $3 \mathrm{~A}_{5} \mathrm{AF}$ and $\mathrm{N}$-benzyl-maleimide revealed that the single diastereoisomer corresponds to the alcohol cis to the ether. Importantly, the new structure is incapable of undergoing retro-DA, which displaced the reaction equilibrium and allowed quantitative formation of $\mathbf{2 a}$. Moreover, the high solubility of $\mathbf{2 a}$ allowed its purification through a simple washing with organic solvents followed by freeze drying. Competitive experiment using stoichiometric proportions of $\mathrm{AF}$, and $3 \mathrm{~A}_{5} \mathrm{AF}$ confirmed that only the latter underwent DA under these conditions, further highlighting the importance of the 3-amido group (See Figure S2).

When attempting the preparation of $\mathbf{2 c}$ to obtain a crystal for Single-crystal X-ray crystallography, fine tuning of the reaction conditions was required. Interestingly, the reaction proceeded with the formation of the hemi-acylaminal $\mathbf{2 c}$ under acidic conditions (buffer $\mathrm{pH}$ 2.6). Under basic conditions (buffer $\mathrm{pH} 8$ and $\mathrm{pH}$ 10), the equilibrium is also shifted to $\mathbf{2 c}$, however hydrolysis of the maleimide hinders the utility of these conditions for the reaction. At $\mathrm{pH} 4$ the reaction afforded the enamine product $\mathbf{1 c}$.

The scope for the enamine from 1 was extended to a variety of $\mathrm{N}$-substituted maleimides (Scheme 4). Purification of the compounds was performed by simple extraction after trapping the excess maleimide with a thiol carboxylate, which widely contrasts with problematic purification steps reported for other 7 -ONB from biomass derived furans.

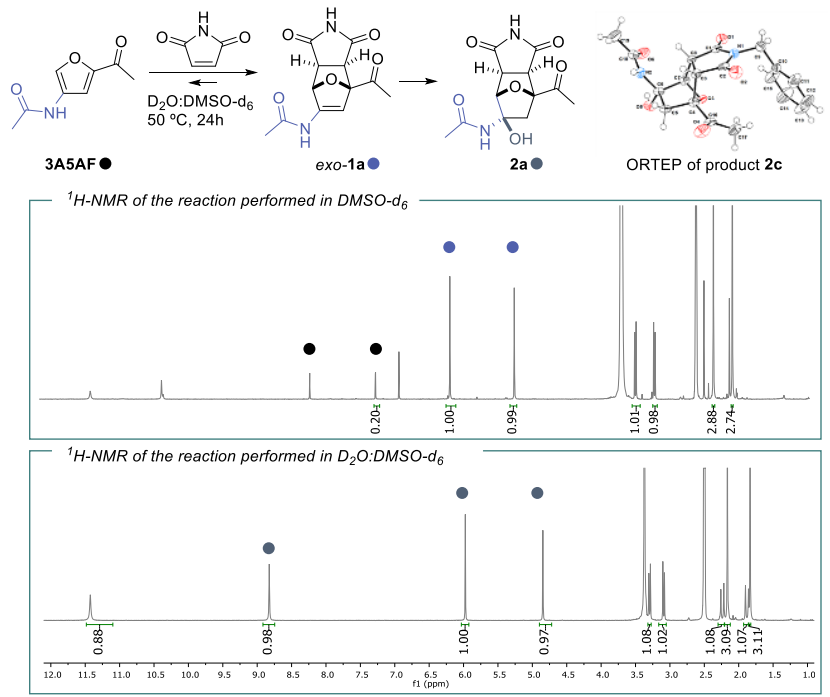

Scheme 3. Unexpected formation of hemi-acylaminal $2 \mathbf{a}$ in water.

Moreover, products also tolerate chromatographic purification, with minimal formation of $\mathbf{2}$ in silica (See Figure $\mathrm{S} 1$ ). The reaction tolerates a variety of $N$-substituted maleimides, including alkyl (1b, 1c), aryl (1d), polar $N$-subtituents such as $\mathrm{C}_{2} \mathrm{H}_{4} \mathrm{OH}(\mathbf{1 e}), \mathrm{C}_{2} \mathrm{H}_{4} \mathrm{OCH}_{3}$ (1f) and $\mathrm{C}_{2} \mathrm{H}_{4} \mathrm{NHBoc}(\mathbf{1 g})$. The DA adducts 1 were obtained in excellent yield with negligible retro cyclization issues, with the exception of $\mathbf{1 a}$ and $\mathbf{1 g}$ where $20 \%$ and $14 \%$ of $3 \mathbf{A}_{5} \mathbf{A F}$, correspondingly, were observed upon column chromatography. Additionally, HPLC studies of the reversible character of the 7-ONB 1c showed full reversibility after $5 \mathrm{~min}$ at $150^{\circ} \mathrm{C}$ (see SI for more information), which goes in line with the desirable properties for the use 7 -ONB in heatresponsive materials.

A scope of hemi-acylaminals was also performed by carrying the reaction at buffered $\mathrm{pH} 2.6$, yielding the desired products $\mathbf{2 a - h}$ often in quantitative yields (Scheme 4 ). The products were easily purified through washing the aqueous media with organic solvent (ethyl acetate) followed by freeze drying.

To showcase the synthetic potential of the novel DA adduct, model reactions were performed with $\mathbf{1 c}$ and $\mathbf{1 d}$ (Scheme 5). Firstly, 7-ONB id underwent acid promoted hydrolysis, yielding ketone 3 in high yield. Secondly, focusing on diversifying the electron rich olefin, epoxidation of $1 \mathrm{c}$ with $m \mathrm{CPBA}$ followed by epoxide opening by 3-chloro-benzoic acid afforded 4 in $58 \%$ yield. Spectroscopic evaluation suggests the isomer depicted in Scheme 5, unfortunately a crystal to elucidate the conformation was unobtainable. Finally, hydrogenation of $\mathbf{1 d}$ with palladium on carbon and $\mathrm{H}_{2}$ furnished $\mathrm{N}$-containing norcantharidin analogue 5 in $80 \%$ yield. 

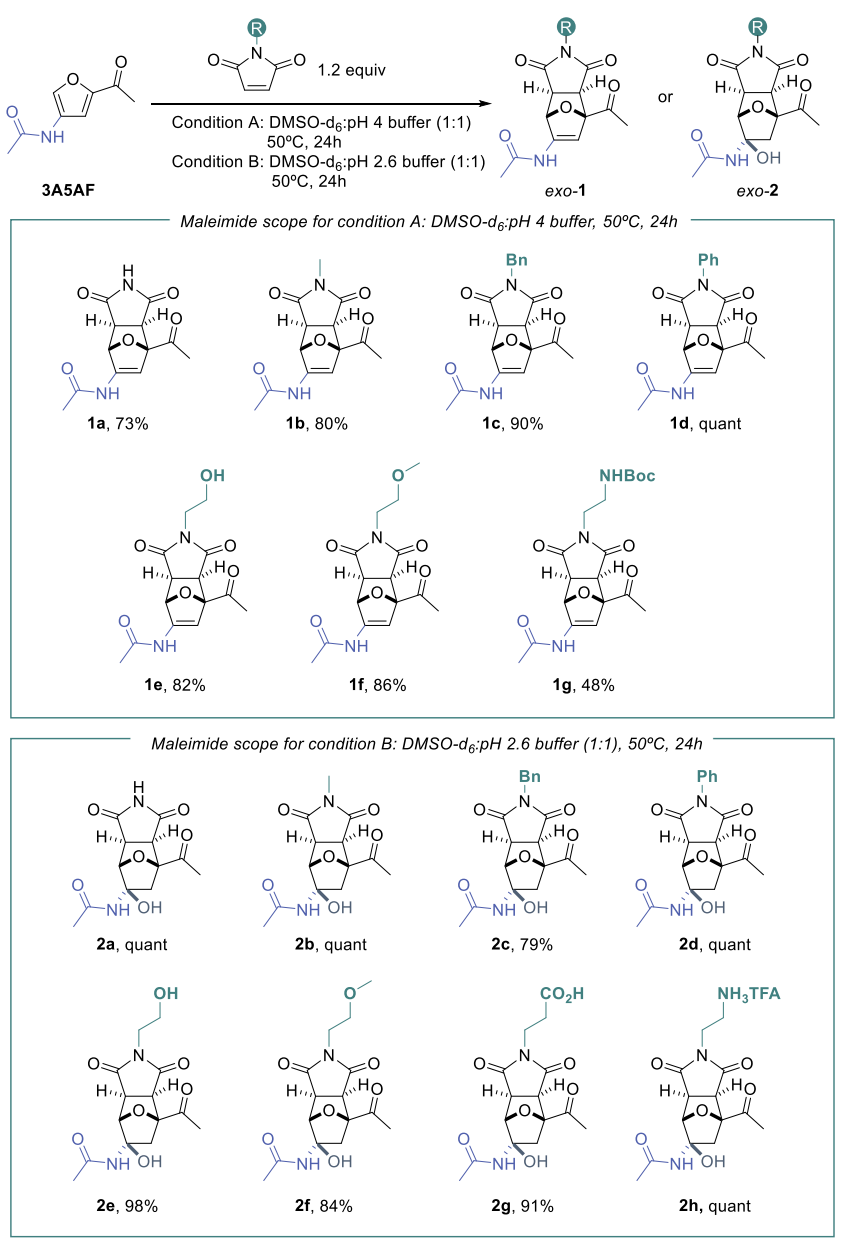

Scheme 4. Scope of the Diels-Alder reaction of $3 \mathrm{~A}_{5} \mathrm{AF}$.

Unfortunately, all attempts at aromatization of 7-ONBs ra-d and hemi-acylaminals $\mathbf{2 a - d}$ either led to no conversion or decomposition (i.e. $80^{\circ} \mathrm{C}$ in $\mathrm{HCl}, 80^{\circ} \mathrm{C}$ in $\mathrm{HBr} / \mathrm{AcOH}$, $0^{\circ} \mathrm{C}$ to $80^{\circ} \mathrm{C}$ in $\mathrm{Ac}_{2} \mathrm{O}$ promoted by $\mathrm{MsOH}$, ${ }^{\circ} \mathrm{C}$ to reflux in DCE promoted by $\mathrm{Cu}(\mathrm{OTf})_{2}$, ${ }^{\mathrm{B}} \mathrm{BuOK}$ in DMSO).

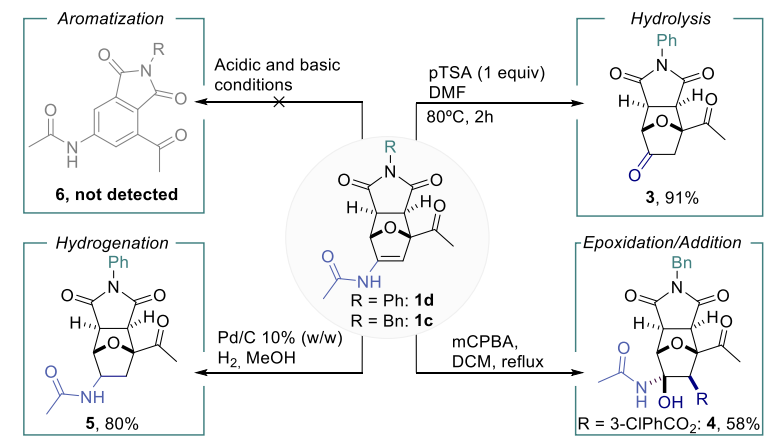

Scheme 5. Synthetic utility of DA adduct.

In line with the reported examples of BHMF and furfuryl alcohol, the corresponding alcohol $\mathbf{7}$ obtained from the reduction of $3 \mathrm{~A}_{5} \mathrm{AF}$ was envisioned to react even faster that the parent ketone. To probe this reactivity, 7 was reacted with $N$-phenyl- maleimide under aqueous conditions (Scheme 6). Indeed the alcohol was remarkably more reactive, achieving $99 \%$ yield at room temperature after 5 minutes. 7 -ONB 8 was isolated as a mixture of diastereoisomers (endo-R, endo-S; exo-R, exo-S).

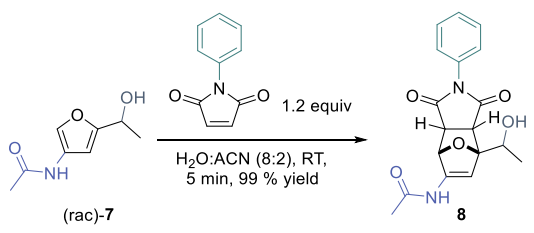

Scheme 6. DA reaction of alcohol 7 obtained from the reduction of $3 \mathrm{~A}_{5} \mathrm{AF}$.

In conclusion, the remarkable effect of the acetamide group in position 3 of the furan endorsed by $a b$ initio studies, allowed for chitin derived $3 \mathrm{~A}_{5} \mathrm{AF}$ to be used as the first biomass furan diene in DA reactions "as is". Fine tuning of the reaction conditions allows selective preparation of 7-oxanorbornenes (7$\mathrm{ONB}$ ) or tandem partial hydrolysis of the enamide to prepare 7-ONB hemi-acylaminal derivatives. Reaction of the corresponding alcohol allowed for a remarkably fast reaction affording the desired product in almost quantitative yield after 5 minutes at room temperature.

The beneficial effect of the 3-acetamide is observed by the mild reaction conditions in contrast with commonly employed harsh conditions which require high temperature or catalysts. Also the operational simplicity for the reaction setup/isolation is highly appealing for its application in areas such as materials, biomaterial chemistry and even biology Nineteen new products were obtained from biomass derived $3 \mathrm{~A} 5 \mathrm{AF}$ in high yields.

This is the first step in expanding the toolbox of ${ }_{3} \mathrm{~A}_{5} \mathrm{AF}$ as diene, highlighting its potential growth into a key synthon for $\mathrm{N}$-containing scaffolds, materials, and commodity aromatics.

\section{ASSOCIATED CONTENT}

Supporting Information. This material is available free of charge via the Internet at http://pubs.acs.org

\section{AUTHOR INFORMATION}

\section{Corresponding Author}

*E-mail: rafael.gomes@campus.ul.pt

\section{Author Contributions}

The manuscript was written through contributions of all authors

Notes

Any additional relevant notes should be placed here.

\section{ACKNOWLEDGMENT}

Financial support from Fundação para a Ciência e a Tecnologia (SFRH/BD/120829/2016; PTDC/QUIQOR/32008/2017; UIDB/04138/2020; UIDP/o4138/2020, $\mathrm{SFRH} / \mathrm{BD} / 120119 / 2016, \mathrm{PD} / \mathrm{BD} / 143162 / 2019)$, is gratefully acknowledged. The project leading to this application has 
received funding from the European Union's Horizon 2020 research and innovation programme under grant agreement No 951996. Fausto Queda would like to thank to Lisboazo2o Programme,Centro 2020 programme, Portugal 2020, European Union, through the European Social Fund who supported LISBOA-05-3559-FSE-000007 and CENTRO-04-3559-FSE-0ooo94 operations as well as to Fundação para a Ciência e Tecnologia (FCT) and Agência Nacional de Inovação (ANI).

\section{ABBREVIATIONS}

DA, Diels-Alder; HMF, 5-hydroxymethylfurfural; 7-ONB, 7oxanorbornenes; FMO, Frontier Molecular Orbital; DiMF, dimethylfuran; BHMF, 2,5-bis(hydroxymethyl)furan; $3 \mathrm{~A}_{5} \mathrm{AF}$, 3 acetamido-5-acetyl-furan; DFT, density functional theory; AF, acetylfuran.

\section{REFERENCES}

1. Kucherov, F. A.; Romashov, L. V.; Averochkin, G. M.; Ananikov, V. P., Biobased C6-Furans in Organic Synthesis and Industry: Cycloaddition Chemistry as a Key Approach to Aromatic Building Blocks. ACS Sustainable Chemistry E Engineering 2021, 9 (8), 3011-3042.

2. Galkin, K. I.; Ananikov, V. P., Intermolecular DielsAlder Cycloadditions of Furfural-Based Chemicals from Renewable Resources: A Focus on the Regio- and Diastereoselectivity in the Reaction with Alkenes. Int J Mol Sci 2021, 22 (21), 11856.

3. Ravasco, J.; Gomes, R. F. A., Recent Advances on Diels-Alder-Driven Preparation of Bio-Based Aromatics. ChemSusChem 2021, 14, 3047-3053.

4. Kucherov, F. A.; Romashov, L. V.; Galkin, K. I.; Ananikov, V. P., Chemical Transformations of BiomassDerived C6-Furanic Platform Chemicals for Sustainable Energy Research, Materials Science, and Synthetic Building Blocks. ACS Sustainable Chemistry E Engineering 2018, 6 (7), 8064-8092.

5. $\quad$ Al Ghatta, A.; Wilton-Ely, J. D. E. T.; Hallett, J. P., From sugars to FDCA: a techno-economic assessment using a design concept based on solvent selection and carbon dioxide emissions. Green Chemistry 2o21, 23 (4), 1716-1733. 6. Bao, L.; Sun, F. Z.; Zhang, G. Y.; Hu, T. L., Aerobic Oxidation of 5-Hydroxymethylfurfural to 2,5-

Furandicarboxylic Acid over Holey 2 D Mn2 $\mathrm{O}_{3}$ Nanoflakes from a Mn-based MOF. ChemSusChem 2o20, 13 (3), 548-555. 7. Pal, P.; Saravanamurugan, S., Recent Advances in the Development of 5-Hydroxymethylfurfural Oxidation with Base (Nonprecious)-Metal-Containing Catalysts.

ChemSusChem 2019, 12 (1), 145-163.

8. Yang, Y.; Mu, T., Electrochemical oxidation of biomass derived 5-hydroxymethylfurfural (HMF): pathway, mechanism, catalysts and coupling reactions. Green Chemistry 2021, 23 (12), 4228-4254.

9. Ulrich, S.; Wang, X.; Rottmar, M.; Rossi, R. M.; Nelson, B. J.; Bruns, N.; Muller, R.; Maniura-Weber, K.; Qin, X. H.; Boesel, L. F., Nano-3D-Printed Photochromic MicroObjects. Small 2021, 17 (26), e2101337.

10. $\quad \mathrm{Xu}, \mathrm{H} . ;$ Hakkarainen, M., Nanostructured Phase Morphology of a Biobased Copolymer for Tough and UV-Resistant Polylactide. ACS Appl. Polym. Mater. 2021, 3 (4), 1973-1982.
11. Hu, B.; Warczinski, L.; Li, X.; Lu, M.; Bitzer, J.; Heidelmann, M.; Eckhard, T.; Fu, Q.; Schulwitz, J.; Merko, M.; Li, M.; Kleist, W.; Hattig, C.; Muhler, M.; Peng, B., Formic Acid-Assisted Selective Hydrogenolysis of $5^{-}$

Hydroxymethylfurfural to 2,5-Dimethylfuran over Bifunctional Pd Nanoparticles Supported on N-Doped Mesoporous Carbon. Angew Chem Int Ed Engl 2021, 6o (12), $6807-6815$.

12. Zhou, B.; Song, F.; Ma, X.; Wang, L., Batch and Continuous-Flow Preparation of Biomass-Derived Furfural Acetals over a $\mathrm{TiO}_{2}$ Nanoparticle-Exfoliated Montmorillonite Composite Catalyst. ChemSusChem 2o21, 14 (11), 2341-2351.

13. Zitouni, A.; Bachir, R.; Bendedouche, W.; Bedrane,

S., Production of bio-jet fuel range hydrocarbons from catalytic HDO of biobased difurfurilydene acetone over $\mathrm{Ni} / \mathrm{SiO}_{2}-\mathrm{ZrO} 2$ catalysts. Fuel 2021, 297.

14. Yang, F.; Zhang, S.; Zhang, Z. C.; Mao, J.; Li, S.; Yin, J.; Zhou, J., A biodiesel additive: etherification of 5-

hydroxymethylfurfural with isobutene to tert-

butoxymethylfurfural. Catalysis Science E Technology 2015, 5 (9), 4602-4612.

15. Gomes, R. F.; Coelho, J. A.; Frade, R. F.; Trindade, A. F.; Afonso, C. A., Synthesis of Symmetric Bis(N-

alkylaniline)triarylmethanes via Friedel-Crafts-Catalyzed Reaction between Secondary Anilines and Aldehydes. J Org Chem 2015, 80 (20), 10404-11.

16. Gomes, R. F. A.; Isca, V. M. S.; Andrade, K.; Rijo, P.; Afonso, C. A. M., Functionalized Cyclopentenones and an Oxime Ether as Antimicrobial Agents. ChemMedChem 2o21, 16, 271-2785.

17. Mascal, M.; Dutta, S., Synthesis of ranitidine

(Zantac) from cellulose-derived 5-(chloromethyl)furfural. Green Chemistry 2011, 13 (11). 3101-3102.

18. Kucherov, F. A.; Galkin, K. I.; Gordeev, E. G.; Ananikov, V. P., Efficient route for the construction of polycyclic systems from bioderived HMF. Green Chemistry 2017, 19 (20), 4858-4864.

19. Lancefield, C. S.; Folker, B.; Cioc, R. C.; Stanciakova, K.; Bulo, R. E.; Lutz, M.; Crockatt, M.; Bruijnincx, P. C. A., Dynamic Trapping as a Selective Route to Renewable Phthalide from Biomass-Derived Furfuryl Alcohol. Angew Chem Int Ed Engl 2020, 59 (52), 23480-23484.

2o. Potts, K. T.; Walsh, E. B., Furfural

dimethylhydrazone: a versatile diene for arene cycloaromatization. J. Org. Chem. 1984, 49, 4099-4101.

21. Jacques, V.; Czarnik, A. W.; Judge, T. M.; Van der

Ploeg, L. H. T; DeWitt, S. H.; Differentiation of

antiinflammatory and

antitumorigenic properties of stabilized enantiomers of thalidomide analogs. Proc Natl Acad Sci U S A 2015, 112 (19), E1471-1479.

22. Potts, K. T.; Walsh, E. B., Furan-2-carbaldehyde Dimethylhydrazones in Diels-Alder Cycloadditions. Journal of Organic Chemistry 1987, 53 (6), 1199-1202.

23. Karaluka, V.; Murata, K.; Masuda, S.; Shiramatsu, Y.; Kawamoto, T.; Hailes, H. C.; Sheppard, T. D.; Kamimura, A., Development of a microwave-assisted sustainable conversion of furfural hydrazones to functionalised phthalimides in ionic liquids. RSC Advances 2018, 8 (40), 22617-22624. 24. Palma, A.; Artelsmair, M.; Wu, G.; Lu, X.; Barrow, S. J.; Uddin, N.; Rosta, E.; Masson, E.; Scherman, O. A., Cucurbit[7]uril as a Supramolecular Artificial Enzyme for 
Diels-Alder Reactions. Angew Chem Int Ed Engl 2017, 56 (49), 15688-15692.

25. Troelsen, N. S.; Shanina, E.; Gonzalez-Romero, D.; Dankova, D.; Jensen, I. S. A.; Sniady, K. J.; Nami, F.; Zhang, H.; Rademacher, C.; Cuenda, A.; Gotfredsen, C. H.; Clausen, M. H., The ${ }_{3} F$ Library: Fluorinated Fsp(3) -Rich Fragments for Expeditious (19) F NMR Based Screening. Angew Chem Int Ed Engl 2020, 59 (6), 2204-2210.

26. Galkin, K. I.; Ananikov, V. P., When Will 5Hydroxymethylfurfural, the "Sleeping Giant" of Sustainable Chemistry, Awaken? ChemSusChem 2019, 12 (13), 2976-2982. 27. Brandvold, T. Carbohydrate route to para-xylene and terephthalic acid. 2010, WO 2010/151346 Al.

28. Thiyagarajan, S.; Genuino, H. C.; van der Waal, J. C.; de Jong, E.; Weckhuysen, B. M.; van Haveren, J.; Bruijnincx, P. C.; van Es, D. S., A Facile Solid-Phase Route to Renewable Aromatic Chemicals from Biobased Furanics. Angew Chem Int Ed Engl 2016, 55 (4), 1368-71.

29. Genuino, H. C.; Thiyagarajan, S.; van der Waal, J. C.; de Jong, E.; van Haveren, J.; van Es, D. S.; Weckhuysen, B. M.; Bruijnincx, P. C., Selectivity Control in the Tandem Aromatization of Bio-Based Furanics Catalyzed by Solid Acids and Palladium. ChemSusChem 2017, 10 (1), 277-286. 30. Thiyagarajan, S.; Genuino, H. C.; Sliwa, M.; van der Waal, J. C.; de Jong, E.; van Haveren, J.; Weckhuysen, B. M.; Bruijnincx, P. C.; van Es, D. S., Substituted Phthalic Anhydrides from Biobased Furanics: A New Approach to Renewable Aromatics. ChemSusChem 2015, 8 (18), 3052-6. 31. Tao, L.; Yan, T.-H.; Li, W.; Zhao, Y.; Zhang, Q.; Liu, Y.-M.; Wright, M. M.; Li, Z.-H.; He, H.-Y.; Cao, Y., Toward an Integrated Conversion of 5-Hydroxymethylfurfural and Ethylene for the Production of Renewable p-Xylene. Chem 2018, 4 (9), 2212-2227.

32. Higson, S.; Subrizi, F.; Sheppard, T. D.; Hailes, H. C., Chemical cascades in water for the synthesis of functionalized aromatics from furfurals. Green Chemistry 2016, 18 (7), 1855-1858.

33. Chang, H.; Huber, G. W.; Dumesic, J. A., ChemicalSwitching Strategy for Synthesis and Controlled Release of Norcantharimides from a Biomass-Derived Chemical. ChemSusChem 2020, 13 (19), 5213-5219.

34. van Scodeller, I.; De Oliveira Vigier, K.; Muller, E.; Ma, C.; Guegan, F.; Wischert, R.; Jerome, F., A Combined
Experimental-Theoretical Study on Diels-Alder Reaction with Bio-Based Furfural: Towards Renewable Aromatics. ChemSusChem 2021, 14 (1), 313-323.

35. Scodeller, I.; Mansouri, S.; Morvan, D.; Muller, E.; de Oliveira Vigier, K.; Wischert, R.; Jerome, F., Synthesis of Renewable meta-Xylylenediamine from Biomass-Derived Furfural. Angew Chem Int Ed Engl 2018, 57 (33), 10510-10514. 36. Muller, E.; Thota, B. Production of tri-methyl benzene derivatives. 2018, World Patent WO2018229237 37. Cioc, R. C.; Lutz, M.; Pidko, E. A.; Crockatt, M.; van der Waal, J. C.; Bruijnincx, P. C. A., Direct Diels-Alder reactions of furfural derivatives with maleimides. Green Chemistry 2021, 23 (1), 367-373.

38. Cioc, R. C.; Smak, T. J.; Crockatt, M.; van der Waal, J. C.; Bruijnincx, P. C. A., Furoic acid and derivatives as atypical dienes in Diels-Alder reactions. Green Chem 2021, 23 (15), 5503-5510.

39. Dai, J.; Li, F.; Fu, X., Towards Shell Biorefinery: Advances in Chemical-Catalytic Conversion of Chitin Biomass to Organonitrogen Chemicals. ChemSusChem 2o2o, 13 (24), 6498-6508.

40. Yan, N.; Chen, X., Don't waste seafood waste. Nature 2015, 524, 13402-13421.

41. Albert Padwa, M. D., Alex G. Waterson, and Tianhua Wu, Diels-Alder Reaction of 2-Amino-Substituted Furans as a Method for Preparing Substituted Anilines. J. Org. Chem. 1997, 62, 4088-4096.

42. Anthony R. Lingham, H. M. H., and Trevor J. Rook, Diels-Alder Reactions of 3-Furylamines in Organic and Aqueous Solvents. Aust. J. Chem 2oo6, 59, 336-339.

43. Averochkin, G. M.; Gordeev, E. G.; Skorobogatko, M. K.; Kucherov, F. A.; Ananikov, V. P., Systematic Study of Aromatic-Ring-Targeted Cycloadditions of 5Hydroxymethylfurfural Platform Chemicals. ChemSusChem 2021, 14 (15), 3110-3123.

44. Ale Meijer, S. O., and Jan B. F. N. Engberts, Effects of the Hydrophobicity of the Reactants on Diels-Alder Reactions in Water. J. Org. Chem. 1998, 63, 8989-8994. 45. Eggelte, T. A., de Koning, H., Huisman, H. O., dielsalder reaction of furan with some dienophiles, Tetrahedron 1973, 29, 2491-2493. 
TOC

In this work $3 \mathrm{~A} 5 \mathrm{AF}$, a biomass derived furan obtained from chitin, is used as diene in Diels-Alder reaction with maleimides. This is the first example of isolated 7-oxanorbornenes containing a ketone moiety obtained from biomass furanics. Moreover, the use of a chitin derivative allows incorporation of bio-based nitrogen in the final products, a challenge unmet by commonly used furanics such as furfural and 5-hydroxymethylfurfural.

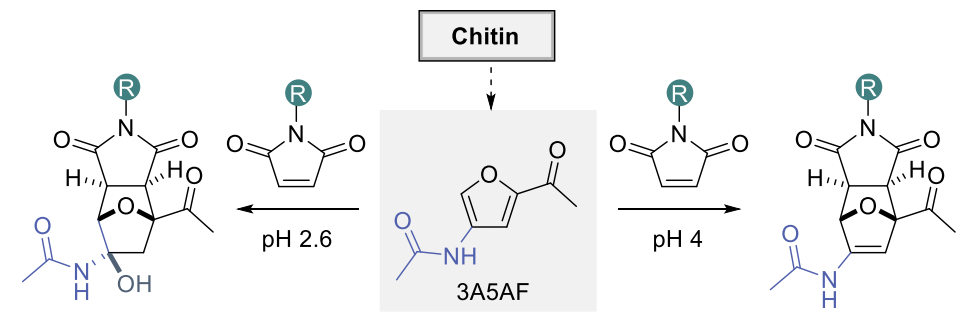

